\title{
Development and Daily Management of an Explicit Strategy of Nonuse of Antimicrobial Drugs in Twelve Danish Organic Dairy Herds
}

\author{
M. Vaarst, ${ }^{\star 1}$ T. W. Bennedsgaard,${ }^{\star}$ I. Klaas, ${ }^{\star}$ T. B. Nissen,† S. M. Thamsborg, $\ddagger$ and S. Østergaard ${ }^{\star}$ \\ ${ }^{*}$ Department of Animal Health, Welfare and Nutrition, Danish Institute of Agricultural Sciences, P.O.Box 50, DK-8830 Tjele, Denmark \\ †Danish Association of Organic Farming, Frederiksgade 72, DK-8000 Århus C \\ $\ddagger$ Danish Centre for Experimental Parasitology, The Royal Veterinary and Agricultural University, 100 Dyrlægevej, \\ DK-1870 Frederiksberg C, Denmark
}

\begin{abstract}
Promotion of animal health and well-being at the individual animal and herd level is an important goal in organic farming. At the same time, chemical products affecting the natural balance among living organisms are prohibited in all areas of the organic farm. From an animal welfare point of view, however, no animal must suffer. Therefore, veterinary drugs are allowed under the European Union's regulations for organic farming, despite the fact that they are powerful cell toxins affecting both pathogenic and necessary bacteria, and as such in organic terminology, are regarded as "chemical" or "artificial" products. In this article, we present and discuss interviews with 12 Danish organic dairy producers who claim that minimized use or nonuse of antimicrobial drugs is an explicit goal. The dairy producers were at different levels with regard to reduced antimicrobial treatment. An explicit strategy of no antimicrobial treatments is based primarily on a long-term effort to improve herd health, and secondarily, on finding alternative treatments for diseased animals. Improved hygiene, outdoor access, use of nursing cows, and blinding of chronic mastitis quarters were the main techniques in developing a strategy of not using antimicrobial treatments in the herd by dairy producers. Producers' perception of disease changed from something unavoidable to a disturbing break in the daily rhythm that often could have been avoided. Change toward a nonantimicrobial strategy was gradual and stepwise. All dairy producers in this study desired to preserve the possibility of using antimicrobial drugs in emergencies.
\end{abstract}

Key words: nonantimicrobial treatment strategy, mastitis treatment, organic dairy farming

\section{INTRODUCTION}

Organic farming is characterized by several goals that are expressed in daily practices and in standards.

Received May 30, 2005.

Accepted November 30, 2005.

${ }^{1}$ Corresponding author: mette.vaarst@agrsci.dk
Some of the important goals for organic production systems are naturalness, harmony on all levels of production, local recycling of resources, and the principle of precaution (Anonymous, 2002). When focusing on the herd, goals for organic farming concerning naturalness and harmony are met by giving the animals opportunities to perform natural behavior and achieve harmony within the group, and to favor freedom of the animals to make as many choices as possible (Alrøe et al., 2001; Lund and Röcklingsberg, 2001; Vaarst et al., 2004; Verhoog et al., 2002, 2004). The production system is not sustainable if animals show evidence of pain, disease, or distress because of an inadequate system or disharmony between the animals and the system. Health and well-being should be promoted in each animal in organic husbandry systems (Lund, 2002; Thamsborg et al., 2004; Verhoog et al., 2004).

A prerequisite for success in any animal production system is the responsibility for maintaining animal health and welfare, managing various crisis and demands, and taking responsibility to intervene when necessary and at the first sign of disharmony. When intervention is necessary to prevent sick animals from suffering, we face potential conflicts and paradoxes within organic animal husbandry. First, many drugs can be regarded as strong toxins disturbing the balance among living organisms (e.g., diarrhea induced by antimicrobial treatments in calves; Rollin et al., 1986). Use of chemical products affecting the natural balance among organisms is prohibited in most areas of the organic farm, except in the animal herd. Justification for their use is the concern for animal welfare: individual animals are not allowed to suffer from disease and must be treated responsibly. This leads to the next relevant discussion: what is a responsible treatment? In the light of the increasing problems with antimicrobial resistance (Aarestrup, 2000), the discussion of responsibility takes several directions that should be addressed. With regard to the animal, overall prognosis of antimicrobial treatments can be discussed in terms of the prognosis for each type of treatment case (e.g., chronic or acute mastitis) and the experience among dairy pro- 
ducers and veterinarians with each antimicrobial product. A relevant example in a dairy herd is mastitis cases involving Staphylococcus aureus bacteria. These cases are reported to have a very poor prognosis for lasting cure even when treated with antimicrobial drugs (Erskine, 2001). Thus, the next obvious question is to determine what else could be done.

Consumers, on the other hand, have expressed their expectations that organic products should be of high quality, including a low risk of drug residues or bacteria that may either cause infection or transfer antimicrobial resistance. They also expect animals to have improved welfare compared with conventional herds (Harper and Makatouni, 2002; Gambelli et al., 2003; Milne, 2003; Midmore et al., 2005). In the United States, the food safety issue is met in a very radical way. According to the National Organic Standards (USDA, 2003), food products from animals treated with any antimicrobial medicine cannot be sold as organic. If an animal receives an antimicrobial treatment in case of a severe disease, it is then removed from the organic food chain. This provision gives a clear signal that organic production has a strong focus on the animal food product and the concerns of consumers regarding a potential risk of being exposed to a product containing residues. In Europe, a similar intention is only expressed through prolonged withdrawal time after treatments and a restriction on only 3 medical treatments per lactation for dairy cows [Council Regulation (EEC) No 2092/91 and No 1804/1999, CONSLEG: 1991R2092 - 01/05/2004].

The discussion of an explicit strategy of nonuse of antimicrobial drugs has reached organic dairy producers in Denmark. Consequently, a pilot study was initiated with the purpose of describing motivations and circumstances under which organic dairy producers had to work when applying an explicit antimicrobial nonuse strategy. Twelve organic dairy producers were interviewed in qualitative research interviews. They had expressed viewpoints about antimicrobial nonuse strategy in their herds, ranging from growing interest but no attempt or experience in practice to reach this goal to several years of experience with active disease prevention and so-called alternative (nonbiomedical) strategies of disease handling. In this article, the results of those interviews are presented and discussed with a focus on relevant questions concerning a strategy of nonuse of antimicrobial agents in the dairy sector based on the case of Danish organic dairy producers and their specific conditions.

\section{MATERIALS AND METHODS}

\section{Selection and Presentation of Herds}

For economic reasons, an interview study of only 12 dairy producers was planned in connection with a proj- ect investigating the risk of antimicrobial resistance in organic dairy farming. A questionnaire was sent to the members of the Association of Organic and Biodynamic Dairy Farmers (100 dairy producers), in which they were asked to express their interest and experience, if any, in phasing out antimicrobial medicines from their dairy herds. Forty-two dairy producers responded to the questionnaire and expressed interest in participating in research activities exploring conditions and consequences of limited use of antimicrobial treatments.

To have as much diversity as possible, the 12 dairy producers were selected according to their location, year of conversion to organic methods, and duration of time that reduction of antimicrobial use had been an explicit goal. Six herds had very low antimicrobial use at the time of selection. The other 6 herds used different amount of antimicrobials, but expressed interest in limiting their use of antimicrobials. Some herd characteristics are presented in Table 1. Each farm was connected to a veterinary practice; however, none of the dairy producers was associated with the same veterinary practice. To evaluate the health status of the selected herds, the main health indicators were calculated for what can be regarded as a control of 76 organic dairy herds selected because they participated in other projects at the Danish Institute of Agricultural Sciences.

\section{Interviews}

All dairy producers were interviewed by means of a qualitative, semistructured research interview in September 2003. All interviews were performed by the same 2 persons (first and fourth authors) and recorded on tape. Interviews lasted approximately $90 \mathrm{~min}$, and the interview followed a 30-min walking tour of the farm. The qualitative research interview is a research method that aims to explore and describe a spectrum of attitudes and experience within a certain field, rather than presenting a representative sample of opinions or quantifying opinions or experience among a group of people (Strauss and Corbin, 1990; Kvale, 1996). Interviews were structured according to a number of thematic questions (Figure 1). The interviewee was encouraged to speak and direct the course of the interview. Interviewers followed up on his or her questions, explored apparently self-contradictory statements, and asked for further examples. The interviewers took responsibility for keeping to the point and the theme of the interview. Thematic questions were weighted differently in the various interviews and were partly directed by the focus of the farm and the interviewee. For example, if homeopathic treatment was widely used in one herd, but not used at all in another, this theme 


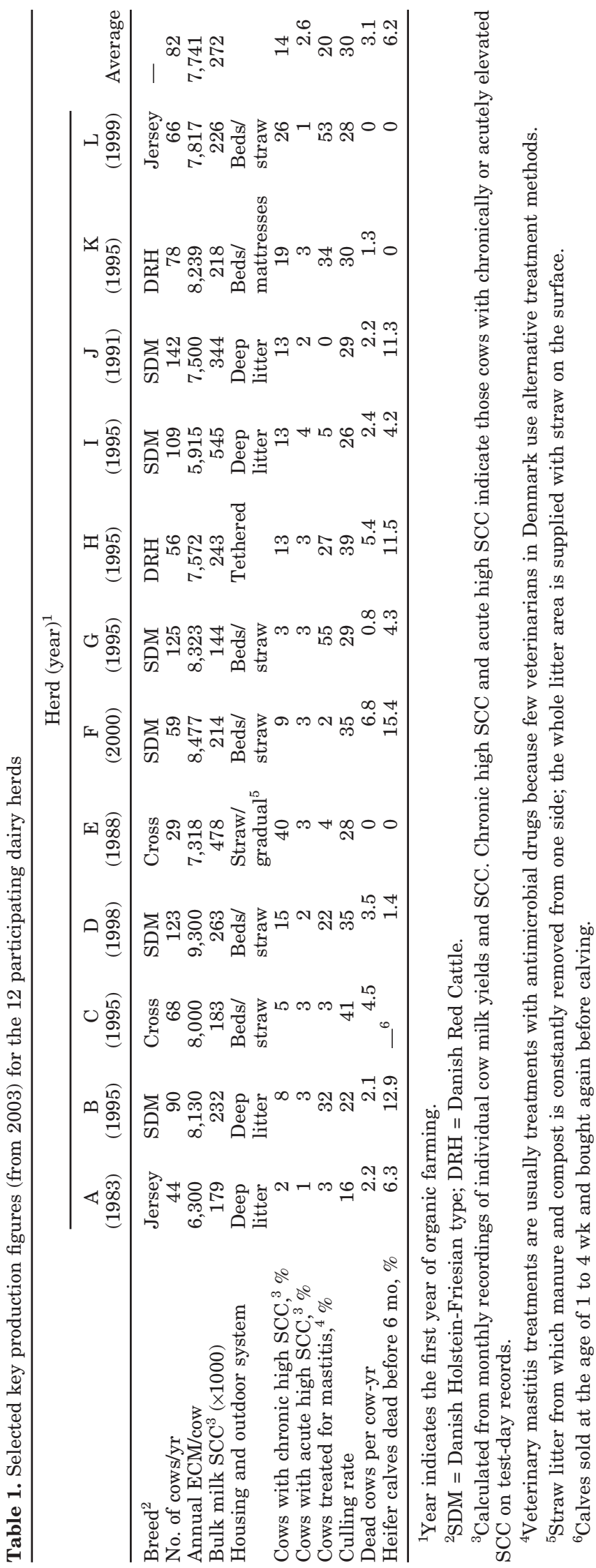

received respectively more or less focus and time during these 12 interviews.

\section{Interview Analysis}

Each interview was taped and a written summary was made and sent to the farmer for confirmation. Quotations of what the farmer said were included in this summary. This approach was chosen to confirm those conclusions and statements of individual dairy producers that were regarded as important. Further, a full transcript was difficult to read and did not contain any interpretation. Overall themes were described across the interviews in an approach modified from Strauss and Corbin (1990). After the themes were described and analyzed, a farmer workshop was held in which the understanding of the relationships among, and the conflicts within, these themes were discussed and confirmed among participants.

\section{Quantitative Data}

Herd data were obtained from the central Danish Cattle Database. Data from monthly or bimonthly milk control were available from all herds. Disease treatments by the veterinarians were reported in the database. Treatments were counted as 1 treatment when they were administered within $9 \mathrm{~d}$ of the first treatment of the disease. Differences between years were analyzed by using procedure GLM with herd and year in the model (SAS Institute, 1999).

\section{RESULTS}

\section{Facilitating Nonantimicrobial Treatment Strategies}

Focus on Improving Herd Health Rather Than Eliminating Antimicrobial Use. Seven dairy producers said that they had had the goal of phasing out antimicrobial treatments in their herds for at least $1 \mathrm{yr}$ (one of whom had considered himself inexperienced with strategies of nonuse of antimicrobial agents). These dairy producers strived to improve health conditions in their herds and create a dairy production system that promoted animal health and welfare and enabled the dairy producer to manage effectively and intervene when necessary. At a certain point in this developmental process, they realized that, as the number of disease treatments decreased, their awareness and motivation to improve the living conditions in the herd increased. All dairy producers emphasized that the avoidance of antimicrobial treatment was a herd goal, but not the first priority compared with generally improved herd health. In Figure 2, we present factors that 


\section{Interview Guide}

Tell me about your way of "phasing out antimicrobials from your herd" - What is the history of this goal and its way of being practiced on your farm? What were your first experiences and how did you proceed? Your doubts (then and now)? When did it become a goal?

Theme 1: Your herd and its daily life (Changes over the last few years - motivations - and which kind of system have you developed, on what background?)

Theme 2: Your animals and how you keep them healthy

(Priorities, changes, routines)

Theme 3: Different ways of handling disease and diseased animals (Own learning process, collaboration, development)

Theme 4: Expectations for the future and future development of the herd

Figure 1. The interview guide used in interviews with farmers/producers to determine their goals and practical handling of the herd, individual animals, and disease cases.

the dairy producers cited as important for improving herd health.

Improved Control of Individual Cows and Housing. Because of making a strategy of antimicrobial nonuse an explicit, distinct goal for the herd, the dairy producers had begun to examine their own choices of disease treatments. They had systematically evaluated which disease cases they had treated by going through lists from the central cattle database and their own logbooks. In doing so, they had reflected upon the results and whether something else could have been done. The veterinarian had normally not been involved in this reflection process. Dairy producers gradually started checking certain cows (e.g., fresh cows) with the California Mastitis Test (CMT) and bacteriological culturing of milk samples in collaboration with the veterinarian.
For up to several years (some of the dairy producers still found themselves in this phase), they gradually changed their responses to a disease case from immediate disease treatment to immediate intense follow-up and frequent checking of the diseased animal. They closely followed up on mastitis cases treated by their veterinarian (in Denmark, veterinarians are allowed to treat organic dairy cows with veterinary drugs), and those they had treated with alternative methods. The choice of how to handle mastitis cases varied among dairy producers and partially depended on producers' individual goals. Some dairy producers expressed the view that their goal was to avoid time-consuming treatments; therefore, they would never focus on alternative treatments, but would blind a quarter in case of a chronic problem. Others saw it as a goal to avoid cows 
- $\quad$ Allowing free access to outdoors all year (except in very bad weather)

- $\quad$ Providing soft bedding with straw

- Intensively managing the bedding, cleaning beds at least twice daily

- Maintaining adequate milking hygiene

- Closely following up on changes in milk, cows, and udders (e.g., frequent testing of milk using the California Mastitis Test or bacteriological culturing)

- Providing ample space, open air, and a very open housing system

- Retaining cows that have proved their value and are robust (keeping older cows; keeping "robust" cows was defined as disease free, having strong legs, uncomplicated calvings, and good milking characteristics)

- Cross-breeding (e.g., systematic use of 3 different breeds)

- Choosing bulls having high breeding index for mastitis resistance

- Providing feeds with good structure to improve rumen function, either combined or not combined with herbs

- Housing dry cows separately where they cannot hear the milking machines and where the drying off process is closely monitored

- Having nurse cows (see description in the text of nurse cow systems) in the herd that are either chronic mastitis cows before culling or acute mild case mastitis cows to be cured and returned to the milking herd

- Drying off glands that had chronic mastitis.

Figure 2. Important health factors as indicated by the participating dairy producers that reflected their perception of a healthy herd.

with blind quarters, and therefore were willing to put effort into a combination of alternative treatment and a culling strategy that matched the goals of the herd concerning bulk tank SCC. Some dairy producers used cows with high SCC as nurse cows for calves less than 3 mo of age. Furthermore, collaboration with the veterinarian was also important (e.g., when sampling and making bacteriological cultures of suspected mastitis cows). In most cases, the farmer exclusively made the decisions and the veterinarian was involved only to perform the bacteriological culturing and to treat the cows, if the farmer decided to use antimicrobial drugs. In 2 cases, the veterinarian was the driving force with regard to homeopathic treatments, but was not directly involved in other decisions on the individual or herd level. 
Gradually Increasing Skepticism and Stepwise Reduction of Antimicrobial Agent Use. Dairy producers who began an antimicrobial nonuse strategy experienced a gradual and stepwise change. As explained above, the goal itself evolved over time, and once becoming a goal, it was still achieved in a stepwise way and involved sporadic antimicrobial treatments in cases in which they were considered necessary. Improvements in the herd were increasingly focused on eliminating the need for disease treatment. Parallel to the realization that treatments in the herd were reduced dramatically over time, the farmer often described increasing skepticism about antimicrobial treatments because of their disappointing results in the herd and the apparently reduced need for them. The dairy producers also described an increasing consciousness of generally unsatisfying treatment results (reduced milk production, chronic changes in the udder, or permanently elevated SCC despite treatment), and said that this had supported the change toward a strategy of nonantimicrobial treatment.

Use of Antimicrobials Should Always Be An Option. All dairy producers indicated that they would not advocate general prohibition of antimicrobial agent use in organic farming. Regardless of their own personal goal of not using it or needing it in their own herds, use of antimicrobial treatments should be an option. The idea of selling or transferring cows to another herd because they were treated once with antimicrobial drugs did not make sense as expressed by farmer E:

"If you just cull the cows and get rid of them, well, then you push the problem away from yourself and onto somebody else. If you see it all in a more overall perspective, then I should be able to-within this closed area, which is my farm-make things work. And if I cannot, then I have to use the tools available ... Because, in reality, this cow still exists. Whether she lives here in my herd or with a conventional farmer, well ... this cow was born here, and has had a good life here, and so she should stay here for the rest of her life - that is my principle."

\section{Daily Disease Management Following a Nonuse Strategy}

Outdoor Access, Improved Bedding Hygiene, and Milking as Key Management Routines. Outdoor access or open housing systems with plentiful fresh air was a management factor that the dairy producers pointed to as important for an environment with low risk for developing infectious diseases, such as mastitis. In all herds, a big effort was made to keep the bedding clean by cleaning them 2 or 3 times every day, very often in relation to milking. Straw bedding was used in all herds, and all the dairy producers stressed that managing bedding was a major daily routine.

Milking was a third key area that dairy producers emphasized as an essential element of generally good health status. In all herds, the same person was involved in milking, and milked at least once every day. Dairy producers considered this a major advantage, because it ensured monitoring every development of each cow in the herd. Further, maintaining the same milking routines over time as well as between milkings was important. In some herds, such as herds F and I, daily herd management was performed by one person almost exclusively, namely the farmer himself; he perceived this as leading to a good "feel" for current herd status. In other herds, such as herd J, where 2 or 3 persons milked cows, a clear system of communication with spray colors on the udder was developed, so that all milkers were aware of cows that needed extra attention.

Characteristics of the Mastitis Cases. All herds experienced mastitis cases that were relatively uncomplicated and did not lead to any serious risk to the life or general health of cows. A"typical" mastitis case was described to involve clots in the milk and one or more slightly swollen quarters, in which appetite was unaffected. Most cows had problems with mastitis in connection with drying off and calving. Drying off as well as calving management differed among herds.

Measuring Mastitis and Follow-Up on Individual Cows. Most of the dairy producers interviewed used control measures such as CMT, premilking strip cup, and collected samples for bacteriological cultures. Using a strip cup was often done in relation to all milkings, and most producers used the monthly SCC measures to select cows for CMT and to identify affected quarters. Dairy producers D and H only had bimonthly, instead of monthly SCC measures, partly to encourage more intensive use of CMT, and because they considered the CMT more informative and valuable than the monthly cow-level SCC. As explained earlier, measuring SCC indirectly by the CMT was most widely done in the first part of the process, in which improved control contributed to "replacement" of immediate treatment. These cases were not ignored, but intensely followed up by the farmer, instead of just treating the cow immediately after having noticed some signs of disease without further evaluation or reflection.

Disease Treatment was a Time-Consuming Break in the Daily Routine. One major reason for avoiding disease rather than considering replacement of antimicrobial treatments with alternative treatments was to reduce disruptions in the daily work routine. Dairy producers making this argument touched 
on both the lack of being able to plan a rational, efficient day and the psychological distress from being confronted by diseased animals and the decision as to how to handle the situation. Dairy producers pointed to the fact that the housing or handling facilities did not allow easy intervention. Cows were housed in large groups and in loose-housing systems, and it was time consuming to catch a single cow for treatment or extra care. One farmer did not reduce antimicrobial treatment during the first year after the interviews, but emphasized that treatment by the veterinarian was the first choice in mastitis cases, because other ways of handling disease were too time consuming. In contrast, farmer B expressed the view that a production system that is what he called "robust" (meaning promoting the animals' health and welfare and at the same time flexible to work with and easy to overview for the farmer) makes the resources for crisis management available:

\begin{abstract}
"We normally have plenty of time in our daily life, and there is plenty of time to take care of our animals in this system, because it is relatively simple - so, we have extra time in case of need for an extra effort - and you can spend that time for a limited period, but we basically do not want to go on for a longer time."
\end{abstract}

Alternative Disease Treatments. Widely different attitudes and approaches were taken to alternative treatments of mastitis cases. Most dairy producers used peppermint ointment for udder massage in mild cases, and did some extra stripping in connection with milking. Farmer F estimated that he used an extra 15 min at every milking for taking care of cows that demanded special care. Some dairy producers, such as dairy producers $\mathrm{D}$ and $\mathrm{C}$, expressed complete lack of interest in alternative treatments and in the idea of paying so much attention to treating diseased cows. They referred to health promotion as their main interest, with the goal that disease should not be allowed to absorb energy and attention. Therefore, when a cow reached the point where it should be treated, they preferred to have it treated with antimicrobial drugs, because that was the easiest approach. Some dairy producers had sporadically tried various alternative products, mostly homeopathic complex remedies, with different levels of success. A few others had developed a treatment practice with homeopathic remedies in collaboration with a veterinarian or other dairy producers.

Suckling as an Alternative to Handling Cows with High SCC. Five of the 12 dairy producers had suckling systems, in which cows nursed 3 to 4 calves each, either in separate pens (1 cow with her calves) or common pens. Suckling systems worked in different ways, but a common feature in 4 herds was that patient, old "good nursing cows" stayed with the newborn calves on a more permanent basis, and developed a bond with them. In some cases, this permanent stay lasted for the 3-mo milk-feeding period. Nurse cows were normally those having elevated SCC, and they often were destined to leave the herd after the nursing period. Parallel to this system, another system was applied in 2 herds with older and more robust calves that were used to nurse a cow. This system was typically more of a shortterm treatment involving cows having elevated SCC or clinical changes in their milk or udders. These cows could remain with nursing calves perhaps 4 to $7 \mathrm{~d}$ and then return to the milking herd.

Drying Off Quarters as a Strategy. Chronic cases of mastitis were often handled by drying off the quarter. In most cases, milk yield from the affected quarter was very small, and in a sense, the cow dried off the quarter herself. Nevertheless, in some cases the farmer had to make an active effort to gradually dry off one quarter by hand milking while machine milking the other quarters. In some herds, such as herd C, up to $33 \%$ of the cows had blind quarters. In many herds, cows having a blind quarter were still inseminated to stay in the herd. In other herds, a blind quarter was a reason for culling. Some dairy producers had experience with blind quarters becoming completely normal again after one calving.

Collaboration with the Veterinarians. Farmer A described a gradual development of common understanding and mutual respect between himself and his veterinarian:

"We have been using the same veterinary practice all these years, and we have developed a good way of collaborating, in particular with one of the vets, so that when he comes to the herd, he may drive away again without having treated any cow, and then I think you have come a long way."

Some dairy producers, such as dairy producers $\mathrm{F}$ and $H$, very specifically said that they used their veterinarian only for treatments when they themselves found it necessary, and that the veterinarians were not interested in advisory service, and had no interest in the dairy producers' goals or to the fact that they were organic. Farmer J felt that he himself normally had a good feeling for the disease situations, and that he had the same knowledge as the veterinarian:

"Without really saying anything negative about the veterinarian, I claim that in more than $90 \%$ of disease cases, we know as well as the vet what is wrong, ... and in the re- 
maining $10 \%$, well, he cannot always do anything anyway, so if we run into a case like that, we hope that the cow will recover; otherwise we will have to shoot her."

\section{Doubts and Feelings of Insecurity Among Dairy Producers Who Have Not Yet Started the Process}

Dairy producers $\mathrm{G}, \mathrm{K}$, and $\mathrm{L}$ were interested in a nonantimicrobial treatment strategy because they had been confronted with the idea and heard it discussed at meetings, but had not yet started the process. In the case of farmer $\mathrm{L}$, the veterinarian had inspired his thoughts about this goal, including the attempt to reach it by herd improvements. This farmer and his veterinarian focused primarily on the treatment strategy and how to prevent disease. To varying degrees, the dairy producers expressed concern about animal welfare in cases of disease when antimicrobial treatment was excluded as a treatment possibility. At the same time, they expressed an increasingly critical and self-examining consciousness about the motivations for using antimicrobial agents as expressed by farmer $\mathrm{K}$ :

"Sometimes it is your own bad conscience that is the true object of treatment ... and you are told that if antimicrobials do not work, then nothing will work - and then it is a damned easy solution."

One characteristic of herd $\mathrm{K}$ was favoritism for certain cows that had received the majority of treatments. Farmer K realized this favoritism, but did not want to cull these cows because he liked them and they had a high milk yield. He chose antimicrobial treatments rather than alternative treatments, because he found that they produced the best prognosis.

\section{Indicators of Herd Health During the First Year After Interviews}

Indicators of herd health for the 1-yr periods before and after the interviews are shown in Table 2. The small number of herds in the study meant that only very large differences in the variables could be expected to show statistical significance. Frequency of mastitis treatments was smaller $(P<0.05)$ in the herds with limited use of antimicrobial agents than in the herds phasing out antimicrobial drugs in 2003, and the control (other organic herds) in 2003 and 2004. Reducing mastitis treatments seen in the herds phasing out antimicrobial drugs did not differ from control organic herds. Reducing mastitis treatments occurred in 40 to $75 \%$ of 4 of 6 herds, an $80 \%$ increase in 1 herd, but no change in the last herd (see Table 1).
Calculated bulk tank SCC was smaller $(P<0.05)$ in the herds phasing out antimicrobial drugs than the herds with limited use of antimicrobials during both years.

\section{DISCUSSION}

\section{Amount of Mastitis and Treatments in Organic Dairy Herds}

As seen from the herd characteristics in Table 1, the dairy producers indicating they wanted to phase out use of antimicrobial drugs were clearly very far from the goal of an antimicrobial nonuse strategy. For example, 1 herd had 55 treatments per 100 cow-yr. Furthermore, the SCC data indicated that most herds struggled to maintain good udder health, regardless of how frequently farmers used antimicrobial treatments.

Mastitis has been identified as the main disease problem in organic dairy herds in most European countries. In many studies, the amount of mastitis in organic herds is similar to or greater than in conventional herds (Krutsinna et al., 1996; Spranger, 1998; Hovi and Roderick, 1999; Weller and Bowling, 2000; Sundrum, 2001; Thamsborg et al., 2004). In Scandinavian countries, generally less mastitis has been found in organic herds (Ebbesvik and Løes, 1994; Vaarst and Enevoldsen, 1994; Vaarst, 1995; Hardeng and Edge, 2001). In organic herds in England and Wales, a large amount of dry cow mastitis has been reported (Hovi and Roderick, 1999). Dry cow therapy is widely used in dairy herds, often as a preventive measure, and as such, used for each cow in the herd at dry off (Hovi, 2003). In Denmark, use of any medical inputs for disease prevention has been prohibited since 1995. This means that dry cow therapy, as a preventive measure, cannot be performed in any herd, conventional or organic. In more recent Danish studies, only a few old organic herds differed from the conventional herds with regard to frequency of treatments and SCC (Danish Cattle Health Advisory Board, 1998; Bennedsgaard et al., 2003). Vaarst (1995) found a very small incidence of treatments as well as relatively little mastitis (based on reduced SCC, few clinical signs, and fewer bacteriological findings) in 15 organic Danish herds that participated in a study of organic farming. At that time, they represented about $25 \%$ of Danish organic dairy cows. These results were achieved by consistent and strict management routines, and immediate intervention after observing signs of mastitis. These interventions involved hand stripping, udder massage using peppermint ointment, and other nonmedical treatments. In Danish studies, this picture is no longer seen, because organic dairy producers generally do not report making 
Table 2. Udder health in 6 herds having limited antimicrobial use, in 6 herds working to phase out antimicrobial use, and in 76 organic dairy herds not involved in the research project

\begin{tabular}{|c|c|c|c|c|c|c|c|}
\hline \multirow[b]{2}{*}{ Group } & \multirow[b]{2}{*}{$\begin{array}{l}\text { No. } \\
\text { of } \\
\text { herds }\end{array}$} & \multirow[b]{2}{*}{$\begin{array}{l}\text { Herd size } \\
\text { (cow-yr) }\end{array}$} & \multirow[b]{2}{*}{$\begin{array}{l}\text { Mastitis } \\
\text { treatment } \\
\text { per } 100 \\
\text { cow-yr }\end{array}$} & \multicolumn{3}{|c|}{$\begin{array}{l}\text { Based on monthly recordings } \\
\text { of individual milk yield and SCC }\end{array}$} & \multirow[b]{2}{*}{$\begin{array}{l}\text { Culling rate } \\
\text { per yr }\end{array}$} \\
\hline & & & & $\begin{array}{l}\text { Calculated } \\
\text { bulk tank } \\
\text { SCC }\end{array}$ & $\begin{array}{l}\text { Cows with } \\
\text { chronic } \\
\text { elevated } \\
\text { SCC, \% }\end{array}$ & $\begin{array}{l}\text { Cows with } \\
\text { acute } \\
\text { elevated } \\
\text { SCC, \% }\end{array}$ & \\
\hline \multicolumn{8}{|c|}{$\begin{array}{l}\text { Limited use of antimicrobial } \\
\text { drugs for }>1 \mathrm{yr}\end{array}$} \\
\hline \multicolumn{8}{|c|}{$\begin{array}{l}\text { Expressing interest in phasing } \\
\text { out antimicrobial drugs }\end{array}$} \\
\hline 2003 & 6 & $90(56-125)$ & $37(22-55)^{b}$ & $221(140-260)^{\mathrm{a}}$ & $14(3-15)$ & $3(1-3)$ & $31 \quad(22-39)$ \\
\hline 2004 & 6 & $87(56-124)$ & $26(7-58)^{\mathrm{ab}}$ & $214(180-220)^{\mathrm{a}}$ & $15(9-18)$ & $3(1-4)$ & $39(24-57)$ \\
\hline \multicolumn{8}{|c|}{ Other organic herds } \\
\hline 2003 & 76 & 105 & $45^{\mathrm{b}}$ & 292 & 30 & 3 & 34 \\
\hline 2004 & 76 & 107 & $41^{\mathrm{b}}$ & 270 & 29 & 3 & 35 \\
\hline
\end{tabular}

${ }^{\mathrm{a}, \mathrm{b}}$ Means having different superscript letters within columns differ $(P<0.05)$.

${ }^{1}$ Numbers in parentheses are minimum and maximum values.

any extraordinary effort (Bennedsgaard et al., 2003; Vaarst et al., 2003).

\section{Focus on Improving Herd Health}

All dairy producers expressed interest in avoiding antimicrobial treatments. Nevertheless, those who seemed to have nearly achieved that goal focused on improving herd health as a prerequisite for eliminating the need for antimicrobial treatments. The history about stepwise and gradual change in perception of these dairy producers is an interesting contrast to the concerns and doubts of those dairy producers whose interest in eliminating antimicrobial treatment was raised at farmer meetings, but where the idea was relatively new and less integrated into the other strategies for the herd. They focused on eliminating treatments instead of avoiding disease as a primary goal. The only farmer that did not succeed in reducing antimicrobial treatment during the first year after the interviews differed from this scenario in emphasizing that treatment by the veterinarian was the first choice in mastitis cases, inasmuch as other ways of handling disease were too time consuming.

All 12 dairy producers interviewed said that they would like antimicrobial treatments to remain an option in emergency cases such as cesareans, severe claw disorders, and severe mastitis. This focus seems relevant and appropriate for finding a balance between the basic ideas of organic farming and the concern for animal welfare (i.e., minimize unnecessary suffering).

\section{Disease Management Following an Antimicrobial Nonuse Strategy}

Some statements made by the dairy producers suggested that they associated an explicit strategy of nonantimicrobial treatment with taking responsibility. In particular, the responsibility is to keep the cow healthy, as described by farmer $\mathrm{E}$ :

"You push the problem away from yourself and onto somebody else.... You should be able to ... make things work. And if I cannot, then I have to use the tools available."

The diseased cow is defined as a failure and as something that the farmer has not handled well enough. How far you can take this argument is a valid question. In a well-working, balanced housing system with a good ration and management focusing on animal welfare, the amount of disease is very low. Some cases can, however, be explained by cow characteristics and a combination of unfavorable conditions. Thamsborg et al. (2004) mentioned feeding and housing as potential risk factors for mastitis. They emphasized that growing evidence exists that mastitis can be controlled under organic production conditions, but it is also the major challenge in organic dairy farming. Vaarst (1995) concluded that the markedly small amount of mastitis compared with conventional herds in the early 1990s was not related to the organic production system in general, but to individual dairy producers' willingness and ability to make an extraordinary effort in their herds. This effort can be claimed to be a characteristic of organic farming in the ideal, but it is definitely not guaranteed, 
and the fact that herd size has been consistently increasing during the past decade in Denmark also raises the question of how to ensure routines in which extra care is provided to cows.

\section{Disease Treatments: An Easy Solution or a Disturbing Break?}

As explained in more detail below, the following statements became a crucial part of the conclusions of this study. A disease treatment (which in practice was often a treatment with antimicrobial drugs) can be viewed as meeting 2 completely contrasting objectives. Some dairy producers see disease treatments as an annoying and disturbing event that interrupts daily routine. Others perceive disease treatment as an easy solution after having done all within herd resources. Still others rely upon the judgment of the veterinarian rather than themselves.

Questioning the Necessity of Medical Treatment. In many herds, disease treatments have become part of daily herd management and are not questioned. The major change in several herds in this study seemed to come when the farmer questioned the option of treating disease. Some of the dairy producers (those who made limited progress in their nonuse strategy) described biomedical disease treatments (i.e., natural science treatments or so-called western medicine) primarily as "easy solutions." When doing so, their starting point was still that disease is a condition that must be accepted. Gradually, incidences of disease seemed to become an increasingly disturbing phenomenon, and every time it occurred, the producers were aware that perhaps it could have been avoided. They begin to view disease as something that should not occur. When disease is viewed that way, all efforts connected to disease treatments are regarded as disturbing breaks in everyday routines, and many of the everyday routines are targeted at health promotion. Disease should still be reacted to, when present, but the situation could have been avoided, leaving time and peace for the normal management routines. The interviews reflect this development that, of course, is gradual and stepwise.

What is a "Responsible" Disease Treatment? No matter whether a disease is treated with veterinary medicine or in any nonmedical way, it still requires farmer resolution. The next relevant question is what constitutes responsible treatment. The earlier statement of farmer $\mathrm{K}$ :

"...sometimes it is your own bad conscience that is the true object of treatment..."

suggests that some treatments may be performed primarily to ease the conscience of the farmer. Treatments with antiobiotics seem to be used when not indicated and when no known efficacy for their use has been demonstrated scientifically. Thus, many such treatments, whether farmer- or veterinarian-directed, are often "feel-good" treatments of the user (i.e., they make the farmer feel like he has done something for the cow even though treatment was a waste of time and product).

The question is whether antimicrobial treatment is the most appropriate way of intervening in case of disease. In Sweden, Ekman et al. (1995) recommended use of antimicrobial drugs based on critical criteria and recommended that all chronic cases not be treated with antimicrobial drugs because it is well documented such treatments have a poor prognosis. Mastitis treatments account for the majority of disease treatments in these herds, and in Danish dairy herds in general.

Potential Consequences of Limiting Treatment Strategy. It is not recommended to keep cows with chronic disease of any kind, and particularly not if the goal is to reduce the frequency of disease treatments. This means that a limited treatment strategy to some extent is in conflict with the idea of keeping favorite cows-farmer $\mathrm{K}$ expressed interest in eliminating the use of antimicrobial drugs from his herd, but wanted to keep his favorite cows. Strategies such as drying off infected quarters raise similar potential conflicts in relation to some farmer definitions of good management and healthy cows (Vaarst et al., 2002).

\section{Collaboration with the Veterinarians}

The local veterinarians were involved in different ways in this process in the 12 herds. In some herds, veterinarian involvement was nearly absent. Some dairy producers regarded veterinarians as technicians who did the bacteriological culturing. In Denmark, many veterinarians do bacteriological cultures of milk as part of their daily routines. This has been a major help in the decision-making process for dairy producers. Veterinarians have regularly expressed concern that a goal of a limited disease treatment, as in organic animal husbandry, can lead to poor animal welfare (Anonymous, 1998). These interviews show that the dairy producers want to eliminate the need for antimicrobial treatments primarily by improving the management and environment of cows. This approach probably should be acknowledged and supported by many veterinarians. Nevertheless, working actively and positively with dairy producers toward these goals demands openness, honest dialog, and a desire to understand the intentions behind this goal and what it means for the herd management, daily routines, and choices. Vaarst et al. (2003) showed in an interview study of newly 
converted organic dairy producers that they used their veterinarians in relation to biomedical disease treatments, but only to a very limited extent when making decisions about health promotion and disease prevention, as well as regarding any alternative treatment methods. The same seems to be true in this study. The goal of dairy producers in the present study is clear: they wanted to eliminate the need for antimicrobial treatments through improved animal health, and they wanted support and guidelines to handle diseased cows in a responsible way that did not compromise animal welfare. They wanted advice on how to achieve this goal, and advisors and veterinarians could be relevant partners in the general improvement of the herd as well as daily sparring partners when any critical situation must be handled. The basic goals of the organic dairy producers should not be questioned, but the ways to reach these goals are appropriate to question. Professional knowledge, interaction, and dialogue seemed to be lacking. It is important for the advisor to make an effort to understand the goals of the dairy producer and find acceptable solutions together. Andersen (2004) discussed the competencies of an advisor, and emphasizes the importance of basing all dialogue and advice on the empathetic understanding of the producer, serving as a reflective practitioner and listener, and contributing with professional knowledge and skills where relevant and agreed upon. Hegelund (2004) has discussed different models of clinical decision making from human medicine, including informed decision making, shared decision making, perfect agent, and paternalism. His study mostly dealt with the disease treatment situation and was based on a case study of a Danish veterinary practice. He concluded that veterinarians often use their superior position (in terms of "scientific knowledge" and their role as expert) to impose their preferences and choice of treatment and management changes upon dairy producers. Zwald et al. (2004) found that organic dairy producers tended to seek advice from other producers, whereas conventional dairy producers got their advice from veterinarians. The dairy producers may choose not to spend their resources in seeking advice from veterinary professionals, and this may be explained by the general lack of innovativeness and open-mindedness toward organic farming among veterinarians. This was also expressed by some of the dairy producers in this study and in a previous study of organic dairy herds (Vaarst et al., 2003).

\section{CONCLUSIONS}

The following conclusions are drawn from results derived from a small sample of Danish organic dairy farmers, who produce under the conditions of the European organic production systems, in which use of antimicrobial drugs is allowed, but followed by increased withdrawal time. Further limitations are invoked in US organic production systems. A gradual long-term effort to improve herd health status must be the basis of an explicit antimicrobial nonuse strategy to meet the intent of acceptable animal welfare within the organic farming concept. All dairy producers in our study said that they would like to have the option of using antimicrobial drugs in emergencies. Despite the effort, the descriptive statistics from participating herds indicated that SCC could be improved greatly, and that most dairy producers who have expressed interest in an antimicrobial nonuse treatment strategy still had a long way to go $1 \mathrm{yr}$ after interviews were conducted. Improved hygiene, outdoor access, use of nursing cows, and drying off infected quarters with chronic mastitis problems were the main strategies used to develop a nonuse treatment strategy. More information on dairy producer attitudes and perceptions in relation to treatment of diseased animals is needed to achieve the goals of high health status and reduced use of medicines.

\section{ACKNOWLEDGMENTS}

The study was conducted by members of 2 projects, the first funded by the Danish Research Centre for Organic Farming (DARCOF; "Use of antimicrobials and occurrence of resistance in organic dairy herds"), and the second by the Directorate for Food, Fisheries and Agro Business Fund for Organic Farming Research ("Networking for health in organic dairy herds"). The authors are grateful to the participating dairy producers for the knowledge and experience they shared with us in an honest and open minded way. We gratefully acknowledge Willie Lockeretz, Tufts University (Boston, MA) for very valuable comments and suggestions regarding this manuscript.

\section{REFERENCES}

Aarestrup, F. 2000. Occurrence, selection and spread of resistance to antimicrobial agents used for growth promotion for food animals in Denmark. APMIS (Suppl. 101).

Alrøe, H. F., M. Vaarst, and E. S. Kristensen. 2001. Does organic farming face distinctive livestock welfare issues? A conceptual analysis. J. Agric. Environ. Ethics 14:275-299.

Andersen, H. J. 2004. Râdgivning. Bevægelse mellem data og dialog. [Advisory service between data and dialogue]. Ph.D. Thesis, Danish Dairy Board, The Royal Veterinary and Agricultural University, Copenhagen.

Anonymous, 1998. Editorial. Danish Vet. J. 81: 337.

Anonymous. 2002. IFOAM Basic Standards for Organic Production and Processing. International Federation of Organic Agriculture Movements (IFOAM): http://www.ifoam.org/standards

Bennedsgaard, T. W., S. M. Thamsborg, M. Vaarst, and C. Enevoldsen. 2003. Eleven years of organic dairy production in Denmark: Herd health and production related to time of conversion and 
compared with conventional production. Livest. Prod. Sci. 80:121-131.

Danish Cattle Health Advisory Board. 1998. Produktionsmæssige konsekvenser af omlægning fra konventionel til økologisk produktion. [Production related consequences of conversion from conventional to organic production]. LK News 178. Newsletter from the Danish Cattle Health Advisory Board.

Ebbesvik, M., and A. K. Løes. 1994. Organic dairy production in Norway - feeding, health, fodder production, nutrient balance and economy - Results from the 30-farm project 1989-1992. In Converting to Organic Agriculture. A. Granstedt and R. Koistinen, ed. Scand. Assoc. Agric. Sci. Rep. 93:35-42.

Ekman, T., A. Franklin, C. H. Sandgren, and P. Jonsson. 1995. Antibiotikapolicy vid behandling av mastit hos ko - 'revisited'. Swedish Vet. J. 47:665-669.

Erskine, R. 2001. Ten Myths of Mastitis Therapy. Pages 60-65 in Proc. NMC-PDPW Milk Quality Conference. Natl. Mastitis Counc., Madison, WI.

Gambelli, D., S. Naspetti, and D. Vairo. 2003. Why are consumers buying organic meat and milk? A qualitative study of the Italian market. Pages 125-141 in Socio-economic aspects of animal health and food safety in organic farming systems, Proc. 1st SAFO Workshop. M. Hovi, A. Martini, and S. Padel, ed.

Hardeng, F., and V. L. Edge. 2001. Mastitis, ketosis and milk fever in 31 organic and 93 conventional Norwegian dairy herds. J. Dairy Sci. 84:2673-2679.

Harper, G. C., and A. Makatouni. 2002. Consumer perception of organic food production and farm animal welfare. Br. Food J. 104:287-299.

Hegelund, A. 2004. Veterinary paradigms and practices. Ph.D. Thesis, The Royal Veterinary and Agricultural University, Copenhagen, Denmark.

Hovi, M. 2003. Approaches to mastitis control in well-established organic dairy herds in England and Wales. Ph.D. Thesis, University of Reading, School of Agriculture, Policy and Development, Veterinary Epidemiology and Economics Research Unit, Reading, UK.

Hovi, M., and S. Roderick. 1999. Mastitis in organic dairy herds results of a two-year survey. Mastitis. The organic perspective. Current Research, Prevention, Treatment and Alternative Solutions for the Dairy Sector. Proc. The Soil Assoc. and Univ. Reading, MAFF. Univ. Reading, UK.

Krutsinna, C., E. Boehncke, and H. J. Hermann. 1996. Organic milk production in Germany. Biol. Agric. Hort. 13:351-358.

Kvale, S. 1996. InterViews. An Introduction to Qualitative Research Interviewing. Sage Publications, Thousand Oaks, CA.

Lund, V. 2002. Ethics and animal welfare in organic animal husbandry - an interdisciplinary approach. Ph.D. Thesis, Department of Animal Environment and Health, Swedish University of Agricultural Sciences, Skara.

Lund, V., and H. Röcklingsberg. 2001. Outlining a conception of animal welfare for organic farming systems. J. Agric. Environ. Ethics 14:391-424.

Midmore, P., S. Naspetti, A.-M. Sherwood, D. Vairo, M. Wier, and R. Zanoli. 2005. Consumer attitudes to quality and safety of organic and low input foods; a review. Report of EU-funded project "Improving Quality and Safety and Reduction of Cost in the European Organic and 'Low Input' Food Supply Chains.” Univ. Wales, Aberystwyth, UK.
Milne, C. E. 2003. Consumer perceptions and production realities. Pages 191-199 in Socio-economic aspects of animal health and food safety in organic farming systems, Proc. 1st SAFO Workshop. M. Hovi, A. Martini, and S. Padel, ed.

Rollin, R. E., K. N. Mero, P. B. Kozisek, and R. W. Phillips. 1986. Diarrhea and malabsorption in calves associated with therapeutic doses of antibiotics: Absorptive and clinical changes. Am. J. Vet. Res. 47:987-991.

SAS Institute. 1999. SAS OnlineDoc. Version 8. SAS Inst. Inc., Cary NC.

Spranger, J. 1998. Richtliniengems̈ße Prävention und Therapie in der Tierhaltung des Ökolandbaus am Beispiel der Mastitis der Kuh. Dtsch. Tieraerztl. Wochenschr. 105:321-323.

Strauss, A., and J. Corbin. 1990. Basics of Qualitative Research Grounded Theory Procedures and Techniques. Sage Publications, Thousand Oaks, CA.

Sundrum, A. 2001. Organic livestock farming - A critical review. Livest. Prod. Sci. 67:207-215.

Thamsborg, S. M., S. Roderick, and A. Sundrum. 2004. Animal health and diseases in organic farming: An overview. Pages 227-252 (Chapter 11) in Animal Health and Welfare in Organic Agriculture. M. Vaarst, S. Roderick, V. Lund, and W. Lockeretz, ed. CABI Publishing, Wallingford, UK.

Vaarst, M. 1995. Sundhed og sygdomshândtering i danske økologiske malkekvægsbesætninger. [Health and disease handling in Danish organic dairy herds]. Ph.D. Thesis, The Royal Veterinary and Agricultural University, Copenhagen, Denmark.

Vaarst, M., and C. Enevoldsen. 1994. Disease control and health in Danish organic dairy herds. In Proc. 4th Zodiac Symp., Biological basis of sustainable animal production, Wageningen, The Netherlands. EAAP Publication 67:211-217.

Vaarst, M., B. Paarup-Laursen, H. Houe, C. Fossing, and H. J. Andersen. 2002. Farmers' choice of medical treatment of mastitis in Danish dairy herds based on qualitative research interviews. J. Dairy Sci. 85:992-1001.

Vaarst, M., S. Roderick, V. Lund, and W. Lockeretz. 2004. Combining ethological thinking and epidemiological knowledge to enhance the naturalness of organic livestock systems. BGS/AAB/COR 2004 Conf. BGS Occ. Symp. No. 37. Organic Farming.

Vaarst, M., S. M. Thamsborg, T. W. Bennedsgaard, H. Houe, C. Enevoldsen, F. M. Aarestrup, and A. De Snoo. 2003. Organic dairy farmers decision making in the first 2 years after conversion in relation to mastitis treatments. Livest. Prod. Sci. 80:109-120.

Verhoog, H., V. Lund, and H. F. Alrøe. 2004. Animal Welfare, Ethics and Organic Farming. Pages 73-94 in Animal Health and Welfare in Organic Agriculture. M. Vaarst, S. Roderick, V. Lund, and W. Lockeretz, ed. CABI Publishing, Wallingford, UK.

Verhoog, H., M. Matze, E. Lammerts van Bueren, and T. Baars. 2002. The role of the concept of the natural (naturalness) in organic farming. J. Agric. Environ. Ethics 16:29-49.

Weller, R. F., and P. J. Bowling. 2000. Health status of dairy herds in organic farming. Vet. Rec. 146:80-81.

Zanoli, R., D. Vairo, and P. Midmore. 2001. Literature review of existing consumer-related studies concerning organic food in $\mathrm{Eu}-$ rope. Report, EU project QLK5-2000-01124 OMIaRD 'Organic Marketing Initiatives and Rural Development'.

Zwald, A. G., P. L. Ruegg, J. B. Kanneene, L. D. Warnick, S. J. Wells, C. Fossler, and L. W. Halbert. 2004. Management practices and reported antimicrobial usage on conventional and organic dairy farms. J. Dairy Sci. 87:191-201. 